\title{
Graphic Analysis of the Issues Related to the Auditing of Natural Resources Assets Liability of Leading Cadres
}

\author{
Xiaoming Qiao \\ Journal Editorial Department, Yunnan Normal University, Kunming, 650092, Yunnan, China
}

Keywords: Leading Cadres, Responsibility for Natural Resources and Assets, Audit Plans

\begin{abstract}
Auditing of responsibility of natural resources and assets by leading cadres is an important measure taken by the state to strengthen the building of ecological civilization and its restriction on power. Now, the responsibility audit of natural resources and assets of leading cadres is a brand new type of auditing. Currently, it is still in the stage of exploration in light of the application of audit object, scope, content, emphasis, procedure, method, evaluation, audit report and audit results. In many aspects, there is no complete audit model, thus, how to define the concept of natural resource assets has become a hotspot. The responsibility of leading cadres in natural resources and assets is facing many problems and needs further study. This paper makes some analysis and discussion so as to initiate and promote auditing of natural resources.
\end{abstract}

\section{Introduction}

The "Resolution of the Central Committee of the Communist Party of China on Some Important Issues concerning the Overall Deepening of Reform", which was reviewed and approved by the Third Plenary Session of the 18th CPC Central Committee, proposed that "to establish an ecological civilization, we must establish a systematic and complete system of ecological civilization and protect the ecological environment through the system; Therefore, it is not only a kind of pressure but also a driving force for the leading cadres to work towards the leading cadres' implementation of the auditing of leaving the assets of natural resources and leading cadres, so as to fully enhance the leadership Cadre's environment, awareness of resource conservation, truly responsible for protecting the environment, ecological protection within the performance of their duties.

\section{The Connotation and the Definition of Natural Resources and Assets}

Natural resources refer to the natural existence of human value. Natural resources are an important material basis for the survival and development of mankind society. They cover a wide range of fields, which include mineral resources, water flow, forests, mountains, grasslands, land, sea and air and other means of production, living resources, animals and Plants and other eco-environmental resources, but also include natural scenery and other tourist resources.

From a basic economic perspective, assets are resources that can be measured in money and bring economic benefits to their owners. The natural resource assets refer to the natural resources that are in line with the characteristics of assets and can be capitalized in the composition of natural resources. In accordance with the asset characteristics of "measurable, measurable, verifiable and tradable", natural resources assets include resources such as minerals, land, forests, grasslands, oceans and seas.

The symbiotic relationship between man and nature is manifested as "a community of people, mountains, water, forests, fields, and lakes." In the management, protection, development and utilization of natural resources, the only water treatment of water, Nursing field only caretaker", will inevitably lead to this loss, eventually resulting in ecological destruction. 


\section{The Connotation, Goals and Practical Significance of the Leading Cadres of Natural Resources Assets Liability Audit}

According to the laws of our country, the state belongs to the natural resources such as mineral resources, forests, water currents and mountains, grasslands, wasteland and beaches of the country and collectives, and the state has the responsibility of management and protection. Governments at all levels as state representatives exercise their power to manage and dispose of natural resource assets in accordance with national laws and regulations as well as to supervise the rational utilization of natural resource assets and effective protection of natural resource assets. As the party committee and government are mainly responsible Of course, the leading cadres of the people should bear the responsibility of managing and protecting natural resource assets.

Auditing of responsibility of natural resources and assets by leading cadres refers to the supervision by the national auditing organs in the verification of the performance of duties and responsibilities of the areas, departments and units that they hold during the tenure of leading cadres in performing their duties of managing, protecting and protecting the natural resources in accordance with laws and policies activity. Specifically, the main task is to manage and protect natural resources, minerals, land, water, forests, oceans and other natural resources and energy-saving and emission reduction, water environment management, prevention and control of air pollution, prevention and control of soil pollution, construction of ecological environment, etc. of leading cadres at all levels The audit supervision of the fulfillment of ecological protection responsibility.

Through examining the measures and effectiveness of leading cadres in fulfilling their responsibility for natural resources and assets, the correct evaluation of the performance of leading cadres in the management of natural resources and resources and environmental protection is objectively reflected in the management of natural resources and assets, the protection of resources and the environment And other issues, clear the relevant responsibilities, accountability, to provide a reliable basis for strengthening the management of leading cadres.

(1) To further strengthen the building of ecological civilization. The 18th CPC National Congress and the Third Plenary Session of the 18th CPC Central Committee made it clear that we must strengthen the building of ecological civilization. The construction of ecological civilization is a systematic and vast project that requires the participation of the whole society. By carrying out audits of responsibility of natural resources and assets of leading cadres, we can promptly find out the problems such as environmental damage, resource destruction and ecological security that exist in the process of ecological civilization construction and make suggestions in a targeted way from the institutional and institutional aspects so as to promote resource conservation and protection Implement the basic state policy of environment, promote the construction of environment-friendly and resource-saving society, and accelerate the construction of ecological civilization.

(2) Continuously strengthen the awareness of responsibility of leading cadres in ecological construction. In the construction of ecological civilization, party and government leading cadres bear important leadership responsibilities for the construction of an ecological civilization system and the protection of the ecological environment in this region. Conducting audits of the responsibility of natural resources and assets of party and government leading cadres to establish a lifelong pursuit system of ecological and environmental damage liability can enable leading cadres at all levels to strengthen their sense of responsibility for ecological construction and break the single train of thought for economic development and more from improving human living environment And the quality of life from the point of view to think about the development path and mode to promote the balanced development of the cause of the region.

(3) Strive to improve the system of ecological civilization system. The construction of ecological civilization is a grand project that involves all aspects and needs a sound system of ecological civilization construction to support it. Carrying out audits on the responsibility of natural resources and assets by leading cadres can find problems such as the lack of systems in the construction of ecological civilization, the imperfect systems, the poor operability of the system and the ineffective 
implementation of the system, and propose to set up systems, improve systems and improve System recommendations, so as to promote the construction of ecological civilization system.

\section{The Object, Scope, Content and Focus of the Leading Cadres of Natural Resources Assets Liability Audit}

\subsection{The Leading Cadres of Natural Resources Assets Liability Audit Object}

So, at the Third Plenary Session of the 18th CPC Central Committee, "carrying out the auditing of outgoing assets of leading cadres in natural resources", is it understood in a literal way that machinery resources assets should be audited exclusively or only by leading cadres who have left their posts? From the perspective of audit, leading cadres to carry out outgoing audit of natural resources assets In order to promote the construction of ecological civilization and promote the implementation of the responsibility of the construction of ecological civilization, if only the departure of leading cadres to carry out the responsibility of natural resources assets audit, because of its If the cadres with the responsibility of natural resources and assets are all included in the audit, they can strengthen the sense of responsibility of all leading cadres in ecological construction to achieve the goal of auditing. Secondly, they can to prevent the emergence of irreversible damage to the daily supervision of the normalization of supervision, the audit of assets and liabilities of leading cadres in carrying out natural resources should include leading cadres and leading cadres in office. Therefore, we believe that from the perspective of responsibility, leading cadres of natural resources and asset liability audit target groups.

\subsection{Leading Cadres of Natural Resources Assets Audit Responsibility of the Time Range}

In terms of time range, including the starting and ending time of leading cadres, in general, is the office of the last three years. In terms of natural resources and assets, the general should include the basic natural resources such as land, minerals, water and forests, and also include natural resources assets such as grasslands and oceans in the scope of audit in accordance with the local endowments of natural resources.

\subsection{The Contents of the Audit of the Responsibility of Natural Resources Assets of Leading Cadres}

To carry out the responsibility of leading cadres in natural resources and assets, the contents of auditing should be determined in accordance with the duties and obligations that leading cadres should perform on natural resource assets due to their positions.

(1) Natural Resources Assets Legislation and policy implementation. Major Auditing Areas for Leading Cadres Compliance with Laws and Regulations Concerning Natural Resources Assets, Implementing the Party's and the State's Relevant Policies, Decisions and Plans for the Deployment, Management of Natural Resources Assets, Establishing and Implementing Medium- and Long-Term Planning, Managing Natural Resources Assets, and Protecting The implementation of policies and systems.

(2) Natural resources assets decision-making. Major Auditing Areas for Leading Cadres Regarding the compliance with major decision-making matters concerning the management, development and protection of natural resources assets, reviewing the establishment of decision-making system, compliance with decision-making procedures, lawfulness of decision-making contents, effect of decision-making and No over-exploitation caused by blind decision-making and loss of waste.

(3) Natural Resources Asset Management. The establishment and perfection of the natural resource assets management system in the regions in which the leading cadres are located; the establishment and improvement of the natural resource asset management system; the establishment and improvement of the natural resource asset management system; the establishment and improvement of natural resource asset inventories and changes; the establishment and improvement of the property rights registration and use control system; Asset allocation, development and 
utilization of natural resource assets.

(4) The protection of natural resources assets. The establishment and perfection of the natural resource assets protection system in the regions in which major leading cadres are audited, the review and examination of the establishment and perfection of the natural resource asset protection system, the investigation and handling of cases involving the destruction of natural resource assets, the recovery of the natural resource assets and the environment, the compensation for natural resource assets damages Happening.

(5) The natural environment protection situation. Major audit of the implementation of leading cadres in areas where the responsibility for the protection of the natural environment to review the implementation of the overall plan of environmental protection, implementation of air pollution prevention and control programs, water pollution prevention and control implementation of the plan, implementation of heavy metal pollution prevention and control planning, implementation of soil pollution prevention and control programs, Environmental assessment of major construction projects, investigate and deal with environmental violations.

\subsection{The Leading Cadres Focus on the Audit of the Responsibility of Natural Resources Assets}

(1) Land resources assets. Focus on the implementation of the overall land use planning review of land use and development is strictly in accordance with the overall planning of land for land use, regional planning, urban planning and other construction land scale and layout meet the overall planning requirements; concerned about the implementation of the responsibility of cultivated land protection objectives, Review the accomplishments of the objectives such as the amount of arable land reserved for basic farmland, the area protected for basic farmland, and annual supplementary farmland and land consolidation tasks, review the implementation of the "Supply, review whether the supply of land is in compliance with the relevant policies, whether the mode and manner of the land supply are legal, compliance and whether the land is beyond the control standards and whether the price accords with the provisions of the State, etc. Paying attention to the development and utilization of land, Levied, not for use, not used, and land idle, inefficient, waste and so on; pay attention to the collection and use of land transfer income, review the land transfer price is fully received, the land transfer price is sufficient Turned over financial accounts, The transfer price arrangements usage.

(2) Mineral resources assets. Focus on the implementation of the overall plan for mineral resources, reviewing whether mineral resources exploration and exploitation are strictly carried out in accordance with the overall plan, whether the annual total amount of protected species is strictly implemented in accordance with the control system and whether the mineral registration and management system is established, paying attention to the examination and approval of mineral resources development, Review the prospecting and mining rights approval is compliance, mining rights and other mining rights transfer process there is a serious loss of state-owned assets, corruption and other issues; attention to mineral resources development and remediation, the review of the existence of undocumented exploration and mining, Cross-border mining and other illegal activities, mine recovery and management and mine land reclamation plan or plan is implemented, whether due to the development of low efficiency caused by mineral loss, waste and environmental damage and so on.

(3) Forest Resources Assets. Focus on the development and protection of forest resources, check whether there are illegal and illegal loggings, whether there is serious soil erosion, check the protection of forest resources and the financing, return of farmland to forest, use and effectiveness of the situation.

(4) Water resources. Focus on the protection of water resources, especially water environment governance, solid waste and other pollution control and environmental protection, concerned about urban and rural residents drinking water sources are not up to standards, sewage treatment plant and garbage disposal site management is not good, the key watershed section of the water quality standards People's health problems of water pollution.

(5) Atmospheric environment protection. Focus on the protection of air and other atmospheric 
resources, grasp the key aspects of industrial structure, energy efficiency, exhaust emissions, dust and other key issues concerned about the increase or decrease of air quality related indicators, check whether there is a serious air pollution in the region, whether to implement the implementation Air pollution control measures and capital investment, use.

\section{Leading Cadres Natural Resources Asset Liability Audit Organization Model, Procedures and Methods}

Leading cadre audit of the responsibility of natural resources and assets is the auditing of the fulfillment of the responsibility of party and government leading cadres in the construction of ecological civilization and the protection of the ecological environment. It is a kind of responsibility audit carried out by the auditing organs. How to organize them? There is no unified regulation yet. Because the object of auditing is the party and government leaders at all levels and the management of cadres, the mode of auditing can be the same as the auditing of the economic responsibility of leading cadres of the Party and the government, namely, the establishment of auditing organs and departments such as discipline inspection, organization, land and water conservancy, forestry, marine and environmental protection The coordination mechanism and joint conference system for auditing the responsibility of natural resources by leading cadres shall be submitted to the joint plan for approval by the head of the local government for approval by the joint meeting, the organization department shall entrust the auditing organ to conduct the auditing, the auditing organ shall submit the auditing results to the organizational department and give play to the joint meeting Arrange and study the utilization of audit results, strengthen the cooperation among various departments and promote the improvement of mechanisms and systems in ecological construction and ecological environment protection.

As far as the audit organization is concerned, it is not yet a unified model to carry out audit on the responsibility of natural resources assets by leading cadres. There is a separate organization to carry out audits on the responsibility of natural resources and assets of leading cadres, which is carried out in conjunction with audit of resources and the environment. Resource and asset liability audit and leading cadre economic responsibility audit carried out together. From the perspective of audit efficiency, combining the auditing of the responsibility of natural resource assets of leading cadres with the audit of economic responsibility of leading cadres not only helps the organizational departments to fully grasp the situation of leading cadres in performing their duties, but also saves the audit resources so that the first instance Therefore, the audit of natural resources and assets of leading cadres and the economic responsibility audit of leading cadres should be combined into a regular audit mode. The following is a resource-saving responsibility audit model.

Before the start of the audit, investigate and understand the ownership, distribution, structure, management, utilization and effectiveness of the natural resources and assets of the regions, departments and units where audited leading cadres are located. By means of visits, seminars and field visits, Responsibilities and funds management, extensive collection of relevant laws and regulations, policies and other information for the implementation of the audit well prepared, the basic procedures are as follows.

One is to send an audit notice, and the auditing organ shall, according to the provisions of the audit law, issue the auditing notice on the liability of natural resources of leading cadres to the audited Party and government leaders and the Party committees, governments, departments and units in the region where they are audited in the first three days of the audit; Audit into the meeting, to the audited leaders of the party and government and the local party committees, governments, departments and units leading cadres to introduce the scope of the responsibility of natural resources assets audit, audit content, audit focus on the audit work arrangements and to meet the requirements of the audit; Third is to conduct an audit interview. After the audit team stationed in the audit leadership, the audited leaders should be interviewed by other leaders, regions, departments and other members of the leadership team to understand the audited leaders in the implementation of natural resources and assets policies and regulations, natural resources, asset management decisions, Resource management, protection of natural resources and assets, 
protection and construction of ecological environment, etc. Fourthly, formulate an audit implementation plan, make an informed understanding of the audit responsibility of natural resources assets of leading cadres based on the annual audit work plan and pre-trial investigations and interviews, , Content, emphasis and people Fifth, the implementation of on-site audits, auditors in accordance with the audit division of labor through audit, statistics, surveys and other methods of leading cadres of natural resources and asset liability audit and according to national auditing standards to do the audit records and audit evidence; Sixth is the preparation of the audit report. After the audit team completes the audit field work according to the requirements of the audit implementation plan, it compiles an audit report on the responsibility of the natural resources assets of the leading cadres according to the annual audit work plan and solicits the opinions of the audited leading cadres and the auditees; Report, decision, the audit team to seek the opinion of audited leading cadres and audited units to form the audit report of the leading cadres natural resources assets audit report submitted to audit institutions, audit agencies audit report to the audited leading cadres and audited units issued Formal leadership cadres natural resources asset liability audit report, the audit report needs to be dealt with matters of punishment must issue an audit decision; eight is to submit the audit results, audit agencies to be audited leading cadres and audited units issued a formal Taking into account the report, but also the formation of leading cadres natural resource assets and liability audit report submitted to the executive heads of local departments and organizations, graphical summary audit procedures.

There are many units involved in the responsibility audit of natural resources assets. There are many types of natural resources assets, such as large time span, multi-level, multi-faceted policies and strong policies. The traditional auditing methods of account books have been difficult to meet the requirements and need to be taken comprehensively during the audit Observation inquiry, audit analysis, inspection and other methods to improve work efficiency.

First, the principle of the same rights and responsibilities. Right to be responsible, right should be equal. The audited leading cadres should bear corresponding responsibilities for their non-performance or improper performance of the responsibility of natural resource assets and the consequent consequences.

Second, the principle of seeking truth from facts the problems that the audited leading cadres should fulfill in their responsibility for the natural resources and assets should be analyzed and viewed comprehensively, historically and objectively. It not only reflects the problems found in auditing truthfully, but also fully considers the responsibility of the audited leading cadres in fulfilling the responsibility of natural resources and assets the actual situation, including the division of responsibilities, historical background, decision-making methods, consequences and effects. Strict distinction should be made between direct responsibility, supervisor responsibility and leadership responsibility, former responsibility and current responsibility, leading cadres 'own responsibility and others' responsibility.

The problems existing in the course of auditing leading cadres in fulfilling the responsibilities of natural resources and assets should be objectively and justly analyzed and viewed. They should not be affected by such factors as the subjective will of the auditors, personal likes and dislikes, etc., nor should they be affected by the duties of different leading cadres in their posts The degree of importance and other factors.

At present, there is no normative regulation at the national level. However, in light of the existing provisions on the responsibility determination of economic responsibility audits of leading cadres, the audit responsibility of natural resources and assets of leading cadres should be based on the audit of leading cadres The auditors found that there are problems in the process of fulfilling the responsibility of natural resources assets, which should be divided into direct responsibility, supervisor responsibility and leadership responsibility.

Refers to the leading cadres in the process of fulfilling the responsibility of natural resources and assets should bear the responsibility for the following acts: First, the direct leadership of cadres themselves in violation of laws and regulations, the relevant provisions of the state and the unit's internal management practices; Second, Order, connive at and shelter the subordinate personnel in 
violation of laws and regulations, the relevant provisions of the state and the internal management practices of the unit; third, the audited leading cadres dereliction of duty, malfeasance behavior; Fourth, without the democratic decision-making, direct discussion of relevant meetings to directly determine, approve, organize The implementation of major natural resource assets has led to serious violations of the laws and regulations, the relevant state provisions and the internal management rules of the units, or caused wastage of major economic losses, the loss of assets of major state-owned natural resources, major environmental damage, and major negative social consequences. Fifth, audited leading cadres themselves (authorize and entrust others) to preside at relevant meetings to discuss or study in other ways, but directly decide, approve and organize the implementation of major natural resource assets without the consent of the majority, resulting in serious violations of laws Regulations, state regulations, or due to poor decisions, mistakes that result in significant economic losses and waste, the behavior of the serious consequences of significant loss of assets of state-owned natural resources, significant environmental damage, significant negative social impact and so on; Sixth else should assume direct responsibility for behavior.

Refers to the responsibility of leading cadres in performing the following acts in the responsibility of natural resources and assets: First, except for direct responsibility, the audited leading cadres shall not perform their duties directly or not properly perform the responsibilities of natural resources and assets; Is the leading cadre of the audit (authorizing, entrusting others) to preside at relevant meetings for discussion or other research, and with the consent of the majority, to decide, approve and organize the implementation of major natural resource assets and cause serious violations of laws and regulations and the state Or the serious economic losses and wastes caused by improper decisions or mistakes made in decision-making, the loss of assets of major state-owned natural resources, major environmental damage, and negative social consequences of major societies. Since the appraisal system of natural resources and assets of leading cadres has not yet formed an evaluation system, the evaluation standards of the responsibility auditing of natural resources and assets of leading cadres are still under exploration. In auditing the actual work, conducting evaluation and evaluation of the natural resources assets of leading cadres should be based on the facts verified by auditing or accreditation, in accordance with the laws, regulations and policies of the state concerning natural resources assets and in combination with the objectives and standards of responsibility assessment of natural resources management of leading cadres, Leading cadres should fulfill the responsibility and responsibility for the natural resource assets of the natural resource assets, and within the scope of the statutory functions and powers, take a combination of qualitative and quantitative methods to make an objective and realistic evaluation of the audited leading cadres in fulfilling the responsibility of the natural resource assets.

Auditing evaluation should adhere to the principle of evaluation according to law, objective and fair, and seeking truth from facts. We should conduct auditing and evaluation on the fulfillment of the legal duties and authorities of leading cadres. Auditing and evaluation should be evaluated on the basis of facts and data without departing from the contents of the auditing and not exceeding audit limits, So as to combine the quantitative and qualitative evaluation objectively with the contents of audit, evaluation and auditing. The audit evaluation not only reflects the performance of audited leading cadres in fulfilling the responsibility of natural resource assets, but also reflects the existing problems so that what should be audited should be audited in accordance with the law, what should be audited, and to what extent. Accurately define the leading cadres should bear the direct responsibility, responsibility and leadership responsibility to ensure that the contents of the audit and audit evaluation consistent evaluation conclusion have sufficient audit evidence support.

\section{The Leadership of the Natural Resources of the Asset Liability Audit Report and the Thinking of the Use of Results}

After auditing the responsibilities of natural resources assets of leading cadres, the auditing organ shall, in accordance with the provisions of the auditing law, issue audit reports on the responsibility of natural resources of leading cadres to the audited leading cadres and their units and, in the light 
of the relevant provisions of the economic responsibility auditing of leading cadres, the organization department shall issue a report on the auditing results of the responsibility of natural resources and assets of leading cadres. Upon completion of all the entrusted work, the auditing organ may submit the comprehensive report on the auditing of natural resources and assets responsibility to the party leaders and government leaders, and fully reflect the auditing work of leading cadres on the responsibility of natural resources and assets.

(1) Read the Audit Report on the Liability of Natural Resources Assets of Leading Cadres in an All-round Way. Audit Report on Asset Liability of Natural Resources by Leading Cadres refers to the audit report issued by the audit department to the audited leading cadres and their units and departments after they have been entrusted by the organizational department to audit the performance of the audited leading cadres and their units and departments in natural resources and assets Its fulfillment of the responsibility of natural resources assets and audit evaluation of statutory audit instruments.

The leading cadres' report on the responsibility for the assets and resources of natural resources shall include the following basic elements: title; symbol (not included in the audit report drafted by the audit team); name of the audited leading cadre and the position held by him or the former post; audited leading cadres The name of the unit in which the unit is located or the name of the original unit to be audited; the name of the audit project; the name of the auditing organ; the date of the report (the date of issuance by the person in charge of the auditing organ).

The audit report on assets and liabilities of leading cadres shall fully and objectively reflect the audit results. The contents of the audit report mainly include: the basis for the audit, that is, the laws and regulations on which the audit is based; the basic conditions for conducting the audit, including the starting and ending time of the audit, the scope of the audit and Contents and methods of auditing; serving status of the leading cadres under audit and their division of labor; major situations in which audited leading cadres perform their responsibilities for assets of natural resources; defining the major issues and liabilities found in auditing; opinions on overall auditing and evaluation; and suggestions for auditing, , Put forward the opinions and suggestions on improving the work to the audited leading cadres and their units or former units in charge, and rectify the demands and remedies.

(2) Carefully try to figure out the audit report on the responsibility of natural resources assets of leading cadres. The leading cadres' report on the audit of assets and resources responsibility for natural resources is based on the audit report, which is condensed and refined. Its substantive content should be consistent with the audit report on the responsibility of natural resources and assets of leading cadres. The leading cadres under audit fulfill the main responsibilities of natural resource assets. The major problems discovered by the audit should be highly summarized. The background, process and details of the problems can not be stated without affecting the reading comprehension of the users of the reports. The definition of responsibility is only stated as what kind of liability should be assumed by the audited leading cadres on the audit findings. The basis and reasons for defining the responsibility can not be stated. Disposal (punishment) basis, treatment (punishment) opinions may not be reflected in the leading cadres report on the results of the audit of natural resources assets liability.

(3) Objectively analyze the comprehensive report on the responsibility audit of natural resources and assets of leading cadres. The comprehensive situation report summarizes, analyzes and summarizes the audits of natural resources assets and liabilities audit projects of the same type, the same batch or a certain stage and are important form for auditing organs to fully utilize the audit results of the responsibility of natural resources assets. Auditing organs find out the root causes of the problems by revealing and analyzing the prevailing, regularity and tendency problems of the leading cadres in fulfilling the responsibility of natural resources assets and propose improved opinions and suggestions so that the party committees, governments and cadre management and supervision departments Overall understanding of the implementation of the responsibility audit of natural resources assets, as well as audit of the audit of the responsibility of the natural resources and assets of the leading cadres audit, better serve the leadership of macro decision-making and 
cadre management and supervision.

The main contents of the comprehensive report include: the status of the audit project, the organization and implementation process, the overall situation of audited leading cadres in fulfilling their responsibilities for natural resource assets, the major problems found in auditing, the analysis of the causes of the problems, the results of handling penalties and audit suggestions.

(4) Accurately grasp the leadership of the natural resources assets liability audit service delivery. The audit report on the responsibility of natural resources of leading cadres shall be served on the audited leading cadre, his unit or his original unit.

The leading cadres' report on the auditing of natural resources assets and liabilities shall be submitted to the chief executive of the government at the corresponding level and be submitted to the chief responsible comrades of the Party committees at the corresponding level if necessary; the organizational departments entrusted to audit shall be submitted to the relevant member units of the coordinating agencies. The audit decision shall be mainly sent to the unit where the leading cadre under audit or the original unit is to be audited.

The comprehensive report on the auditing of assets and liabilities of natural resources by leading cadres shall be submitted to the administrative head of the government at the corresponding level for submission to the organizational department entrusted with the audit and, if necessary, submitted to the chief responsible comrades of the Party committees at the corresponding level for copying to the relevant member units of the coordinating agency.

Leading cadres use natural resources and assets audit results of the main body and form. Leading cadres The main body of audit results of the responsibility for the use of natural resources assets include the party committee and government, cadre management and supervision department, the unit under audit of leading cadres or the original unit, other agencies.

Party committees and governments make comprehensive use of the audit results on the basis of audit reports on the responsibility of natural resources assets of leading cadres submitted by auditing agencies, comprehensive reports, special reports and briefings. The main forms include:

The first is to study the system, mechanism and institutional issues concerning the management and protection of natural resources assets reflected in the audit results, and timely study the formulation and revision of the relevant provisions and documents. On the management of natural resources assets, the protection of the prevalence, tendencies and signs of problems, improve the prevention and solution to the problem of institutional measures. We should establish and improve the management and supervision system for leading cadres, formulate scientific assessment and evaluation methods, improve the mechanism for selecting and employing people, and provide guarantee for the construction of ecological civilization.

The second is to establish and improve the reporting system of responsibility audit of natural resources and assets of leading cadres, the rectification of audit work, and the application of the results through accountability. Organize the rectification of the audited leading cadres and their units or former units, and the relevant departments in charge of the implementation of the audit results. When necessary, relevant departments may be organized to conduct inquiry and accountability on the leading cadres under audit. Gradually explore and implement the audit results announcement system.

Third, aiming at the major disciplinary violations committed by leading cadres and relevant personnel disclosed in the report on the auditing of the responsibility of natural resources and assets by leading cadres, the party discipline and political discipline was punished in accordance with the law. The audited leading cadres who performed well in the fulfillment of their responsibilities for natural resources assets were commended and rewarded.

The open audit results refer to the disclosure of the basic situation of auditing of responsibility of natural resources assets by leading cadres, major problems detected by auditing, and the implementation of rectification and reform in accordance with the prescribed procedures. They should be made public within a certain range in an appropriate manner. 


\section{Conclusions}

To sum up, we believe that in conducting audits on responsibility of natural resources of leading cadres, we need to further explore the auditing objects, scope, contents, priorities, auditing procedures, auditing methods, auditing and evaluation, and auditing of natural resources assets and liabilities auditing Reports and the use of audit results and many other issues, but also yet to be established and perfecting the laws and regulations on the auditing of responsibility of natural resources and assets of leading cadres, perfecting the performance appraisal and accountability system for leading cadres, and establishing a linkage working mechanism for the supervision and administration of audit of natural resources and assets And other aspects of in-depth exploration and research to promote leading cadres audit of natural resources and assets into the responsibility of national ecological civilization construction system an important part of further promote the ecological civilization construction in-depth development.

\section{References}

[1] Yan Wei. A Review of Research on Methods of Resource and Environment Auditing [J]. Business Times, 2013 (18):12.

[2] Fu Xuemei. Research on the Auditing Problems of Leader of the Party and Government in Administrative Institutions [J]. Journal of Economic Research, 2013 (34):123.

[3] Yu Yulin. Based on ecological civilization to establish ecological accounting environment [J]. Green Accounting, 2014(1):45.

[4] Zhao Mei. Leading Cadres Natural Resources Assets Outgoing Audit Evaluation System Design [J]. China Auditing, 2014 (3):67.

[5] Peng Chenshui. Reflections on leading cadres to implement the audit of leaving the resources of natural resources [J]. China's national conditions, 2014 (4):74.

[6] Lin Zhonghua. Leading cadres of natural resources assets leaving audit discussion [J]. Auditing Research, 2014 (5):87.

[7] Zhu Suyue. Summer Crystal. Reflections on the audit of natural resources assets leaving the audit [J]. Accounting Research, 2014 (5):46.

[8] Xiao Zhendong. Leading cadres of natural resources assets leaving the audit [N]. China Auditing, 2014-6-4.79.

[9] Ye Xiaogang. The main content of the natural resources assets leaving auditing [J]. China Auditing, 2014 (12):34.

[10] Zhang Yongxiang. Leading cadres to implement the audit of natural resources and assets leaving the audit [J]. Audit Monthly, 2014(12):69.

[11] Ma Yuhong. Reflections on Conducting Audit of Natural Resources Assets Liability of Leading Cadres [J]. Neural Audit and Economic Research, 2015 (6):84.

[12] Qian Shuixiang. Leading cadres of natural resources assets leaving audit research [J]. Zhejiang Social Sciences, 2016 (3):23. 